\title{
Introduction to APPC-2018, a Special Issue of the Journal of Productivity Analysis, "Novel Applications of Efficiency and Productivity Analyses in the Asia-Pacific Region"
}

\author{
Jeong-Dong Lee ${ }^{1} \cdot$ Almas Heshmati ${ }^{2,3}$ \\ Published online: 10 December 2019 \\ (c) Springer Science+Business Media, LLC, part of Springer Nature 2019
}

This special issue is based on papers presented at the Asia Pacific Productivity Conference (APPC, 2018) held at Seoul National University on July 4-6, 2018. A number of submissions were processed by the Guest Editors and finally nine papers, mostly with applications in the Asia-Pacific region were accepted for publication in this special issue. The papers are grouped into two: studies on total factor productivity (TFP) and efficiency. A summary of the papers is given below along with their contributions to existing research.

\section{A. Productivity studies}

The first group of papers relate to total factor productivity. These deal with measuring and decomposing productivity and identifying factors that influence productivity with applications in different areas.

Bert M. Balk in his study "A Novel Decomposition of Aggregate Total Factor Productivity Change" views an industry as an ensemble of individual firms and an economy as an ensemble of industries. In terms of national accounts, the nominal value-added produced by an industry or an economy is the simple sum of firm- or industry-specific nominal value added. From this point of view, one can expect a relation between aggregate industry or economy productivity and the disaggregated firm- or industry-specific productivity. This paper develops a new decomposition approach. A notable difference between its

\footnotetext{
Jeong-Dong Lee

leejd@snu.ac.kr

Seoul National University, Seoul, Korea

2 Sogang University, Seoul, Korea

3 Jonkoping International Business School, Jonkoping, Sweden
}

approach and the earlier approaches is that development is cast in terms of levels rather than indices. It discusses various aspects of this new decomposition and links them to decompositions in existing literature. The paper concludes that one can do away with the usual neo-classical assumptions.

The study by Heesun Jang, Hyunhee Kim, and Hojeong Park titled "A Spatiotemporal Analysis of Korean Ginseng Farm Productivity" contributes to the debate on identifying production functions and controlling for unobserved productivity in estimating the production function. Literature suggests that this identification can be done using panel data or repeated cross-sections. This paper proposes estimating the non-parametric control function based on repeated cross-sections of Korean ginseng farms during 2006-2013 to examine the evolution of farm-level productivity over time and across major production regions. The results show that material inputs' coefficients are underestimated in the OLS regressions; this is consistent with data that farms in the large ginseng production regions use relatively less material than those in the other regions.

The study "Estimation of Technical Change and TFP Growth based on Observable Technology Shifters" by Almas Heshmati and Masoomeh Rashidghalam estimates TFP parametrically. The model is a generalization of the traditional production function model where technology is represented by a time trend. It decomposes TFP growth into an unobservable time trend induced technical change, scale economies, and an observable technology shifter index's components. Its empirical results are based on unbalanced panel data at the global level for 190 countries observed over the period 1996-2013. It uses a number of exogenous productivity growth factors in modeling four technology shifter indices to explore 
development infrastructure, finance, technology, and the human development determinants of TFP growth. The results show that unobservable technical changes remain the most important component of TFP growth.

Finn R. Førsund and Ke Wang in their study "Measures of Industry Productivity Change: The Case of Thermal Electricity Generation in Chinese Provinces 2000-2014" show that a framework for applied production theory at the level of the industry should focus on the crucial features of the industry being studied. These include making a distinction between the theoretical production possibilities before and after investments in micro units; making a distinction between production possibilities at the micro level and the aggregate production possibilities for the industry as a whole; entry and exit of plants, and embodied technological changes at the micro or plant level; and limitations associated with plant level data requirements. The paper applies these concepts of the production function to coal-fired electricity generation aggregated to the Chinese province level and gets valuable structural information for a policy analysis. It also estimates and discusses developments in total variable factor productivity and biases in technical changes.

The study titled "How to Survive and Compete: The Impact of Information Asymmetry on Productivity" by Man Jin, Huiting Tian, and Subal C. Kumbhakar studies the impact of information asymmetry on productivity through the FDI channel. Higher information asymmetry (lower transparency) could increase information costs for investors. FDI is an important determinant of productivity growth. These two key economic variables are connected. The paper uses data from China's publicly listed manufacturing firms as an illustration. The authors find that information asymmetry affects the productivity of domestic firms both positively and negatively, depending on the firms' technology-intensity. Lower information asymmetry associated with more FDI, results in higher productivity. When domestic firms are non-technology-intensive, they can be hurt by foreign competition. Here lower information asymmetry results in lower productivity.

B. Efficiency studies

The second group of papers are related to stochastic frontier efficiency analyses. The applications involve the manufacturing industry and hospitals as well as the collaboration between the contributing authors of JPA who are from various countries, institutes, and disciplines which possibly affects the quality of the papers.

The study which is related to both efficiency and productivity, "TFP Change and its Components for Swedish Manufacturing Firms During the 2008-09 Financial Crisis" by Pontus Mattsson, Pontus Mattsson, and Jonas Månsson views manufacturing TFP as a driving force of economic growth. It investigates TFP change and its components for the Swedish manufacturing industry and compares it with the private service sector during 1997-2013, centering on the negative growth effects of the financial crisis. It uses a stochastic frontier analysis (SFA) to disentangle persistent and transient efficiency from firm heterogeneity and random noise respectively. In addition, it also identifies technical change, returns to scale, and scale change components. It finds that TFP change is lower between 2007-2013 compared to 1997-2007 because of lower technological progress. The paper recommends that policies should target interventions that enhance the technology levels of less productive firms.

The study by Nan Jiang and Antony Andrews titled "Efficiency of New Zealand's District Health Boards in Providing Hospital Services: A Stochastic Frontier Analysis" concludes that efficiency studies are insufficient for improving the performance of public healthcare services in New Zealand. Using a multifaceted administrative hospital dataset, this study measures both the technical and cost efficiencies of hospitals during the period 2011-2017. It deals with the question of how hospital efficiency varies with respect to activities accounted for by the National Health Targets. The empirical results show no evidence that these targets are achieved at the expense of lowering the overall efficiency of hospital operations.

The study, "Allocation of Resources within Subgroups of an Industry: A Case Study in the Chinese Industrial Sector" by Chun-kei Tsang and Sung-ko Li investigates regional fragmentation and ownership distortions which are bottlenecks in economic growth and are two important policy concerns for the Chinese government. This paper measures structural efficiency of a group of firms for 2005-2014 to evaluate such issues using the output-oriented solution method. The authors find that resources are allocated efficiently among different regions but not within the regions. Further, resources are allocated efficiently within different ownerships but not among ownerships. Specifically, by eliminating inefficient resource allocations among different ownerships, the output of the whole industrial sector can be increased by 21 percent of the observed levels.

The last study titled "Research Collaborations in the Journal of Productivity Analysis" by Hyun-do Choi and Dong-hyun $\mathrm{Oh}$ studies collaborations 
between the contributing authors of JPA who are from various countries, institutes, and disciplines which affects the quality of their articles. Drawing from information from bibliographic articles in JPA, this paper finds stylized facts from author and keyword networks, and the efficiency of JPA's major authors. The authors examine research collaborations' effects on JPA by using a research impact measurement technique. Their empirical findings show that author and keyword networks have changed over time, and that collaborations across various authors, institution types, and continents have increased the impact of the research.

The Guest Editors and the journal are grateful to numerous referees for their professional evaluations of the manuscripts. Most manuscripts were revised in three rounds for which we are grateful to the referees' patience, professionalism, and contributions in helping us to improve the quality of the papers. 